\title{
Performance Evaluation of Grid-Connected Wind Turbine Generators
}

\author{
Henok Ayele Behabtu 1,2,*D, Thierry Coosemans ${ }^{1} \mathbb{D}$, Maitane Berecibar ${ }^{1}$, Kinde Anlay Fante ${ }^{2} \mathbb{D}$, \\ Abraham Alem Kebede ${ }^{1,2} \mathbb{D}^{\text {, Joeri Van Mierlo }}{ }^{1}$ and Maarten Messagie $^{1}$ \\ 1 Mobility, Logistics and Automotive Technology Research Centre, Vrije Universiteit Brussels, Pleinlaan 2, \\ 1050 Brussels, Belgium; Thierry.coosemans@vub.be (T.C.); maitane.berecibar@vub.be (M.B.); \\ abraham.alem.kebede@vub.be (A.A.K.); joeri.van.mierlo@vub.be (J.V.M.); maarten.messagie@vub.be (M.M.) \\ 2 Faculty of Electrical and Computer Engineering, Jimma Institute of Technology, Jimma University, \\ Jimma P.O. Box 378, Ethiopia; kinde.anlay@ju.edu.et \\ * Correspondence: henok.ayele.behabtu@vub.be; Tel.: +32-485659951 (ext. +251-926434658)
}

Citation: Behabtu, H.A.; Coosemans,

T.; Berecibar, M.; Fante, K.A.; Kebede,

A.A.; Mierlo, J.V.; Messagie, M.

Performance Evaluation of Grid-Connected Wind Turbine Generators. Energies 2021, 14, 6807. https://doi.org/10.3390/ en14206807

Academic Editor: Davide Astolfi

Received: 3 September 2021

Accepted: 15 October 2021

Published: 18 October 2021

Publisher's Note: MDPI stays neutral with regard to jurisdictional claims in published maps and institutional affiliations.

Copyright: (c) 2021 by the authors. Licensee MDPI, Basel, Switzerland. This article is an open access article distributed under the terms and conditions of the Creative Commons Attribution (CC BY) license (https:// creativecommons.org/licenses/by/ $4.0 /)$.
Abstract: The risk of oscillation of grid-connected wind turbine generators (WTGs) is well known, making it all the more important to understand the characteristics of different WTGs and analyze their performance so that the problems' causes are identified and resolved. While many studies have evaluated the performance of grid-connected WTGs, most lack clarity and precision in the modeling and simulation techniques used. Moreover, most of the literature focuses on a single mode of operation of WTGs to analyze their performances. Therefore, this paper updates the literature by considering the different operating conditions for WTGs. Using MATLAB/SIMULINK it expands the evaluation to the full range of vulnerabilities of WTGs: from the wind turbine to grid connection. A network representing grid-connected squirrel-cage induction generator (SCIG) and doubly-fed induction generator (DFIG) wind turbines are selected for simulation. The performances of SCIG and DFIG wind turbines are evaluated in terms of their energy generation capacity during constant rated wind speed, variable wind speed, and ability of fault-ride through during dynamic system transient operating conditions. The simulation results show the performance of DFIG is better than SCIG in terms of its energy generation capacity during variable wind speed conditions and active and reactive power control capability during steady-state and transient operating conditions. As a result, DFIG wind turbine is more suitable for large-scale wind power plants connected to weak utility grid applications than SCIG.

Keywords: grid integration; wind turbine generator; MATLAB/SIMULINK; variable wind speed operation condition; performance evaluation; DFIG wind turbine; SCIG wind turbine; steady-state operation condition; transient operation condition

\section{Introduction}

Due to limited resources of conventional energy generation sources like fossil fuels and, more importantly, their negative impact on the environment, the installed capacity of renewable energy sources such as wind and solar is rapidly increasing [1]. Data from the International Renewable Energy Agency (IRENA) shows that, at the end of 2020, global renewable energy generation capacity had reached 2799 GW. Hydropower accounted for the largest share of the global total, with a capacity of $1211 \mathrm{GW}$ (excluding pure pumped storage), followed by wind energy (733 GW), solar energy (714 GW), bioenergy (127 GW), geothermal energy (14 GW), and marine energy (500 MW) [2]. Furthermore, regionally Asia accounted for the largest share of renewable generation capacity reached 1.29 TW (46\% of the global total). A considerable part of this increase occurred in China [2]. Compared with solar and other renewable energy sources, wind energy is rapidly growing in the renewable energy sector for electric production. Wind energy is overgrowing because wind turbines release less $\mathrm{CO}_{2}$ to the atmosphere, produce more power, are technologically mature, and 
are relatively cost competitive with traditional sources [1,3].However, the energy generated from wind turbines is not a dispatchable energy source due to the unpredictable nature of wind speed; this means that the generated wind power is more likely to be effectively utilized when a good correlation exists between demand and supply [4]. In addition to this, integrating a large number of wind power plants (WPP) into the utility grid system has several impacts on the power system, including demand and supply power being unbalanced due to the intermittency nature of wind energy; system frequency, and voltage deviation due to power mismatch between the generation and load; slow fault clearance time of wind turbines; and power quality issues caused by the presence of power electronics interfaces in the variable speed wind turbine (VSWT) [5].

Moreover, when a large-scale WPP is integrated with the utility grid system, it must fulfill the grid code standards, especially related to the power quality matters, including voltage variations, flicker, harmonics and inter harmonics, and power factor [4]. These negative impacts of integrating a large-scale WPP into the grid system may disturb or reduce the grid stability. According to the analysis presented in [6], connecting a large-scale WPP to a weak grid system using induction generators can cause power quality problems such as current harmonics, reactive power, and power factor-related issues. The authors of [7] also analyzed the impacts of a doubly-fed induction generator (DFIG) wind turbine connected to a $0.4 \mathrm{kV}$ three-phase network. The investigation of the system performance under steady-state and transient conditions is conducted in this work. The simulation is performed by considering different scenarios such as variable wind speed, network voltage dip, and single-phase fault conditions in the network.

Similarly, the authors of [1] compared the performances of induction generators (IG), DFIG, and permanent magnet synchronous generator (PMSG) types of wind turbines connected to the power system. The efficiencies of the machines are evaluated by considering a three-phase fault at the end of a transmission line. In [8], the performance of grid-connected five-phase modular PMSG with different slot and pole number combinations is evaluated using MATLAB software.

Moreover, other studies [5] discussed the technical challenges of integrating wind energy into a grid system. The advantages and limitations of different types WTGs are identified. In [4], the main challenges of wind energy grid integration, such as the effects of wind power on the power system, the power system operating cost, power quality, and power imbalances, are presented. In [9], the characteristics of VSWT integrated into the weak grid and its operating during a fault, and the normal conditions are examined. In [10], the comparison study between squirrel-cage induction generator (SCIG) and DFIG grid integration impact is investigated. The authors of [11] compared the performances of three different types of WTGs in terms of their power quality performances. [12] simulated a DFIG wind turbine connected to a grid system using MATLAB/SIMULINK. Similarly, in [13], the impacts of connecting DFIG to the grid system are modeled and analyzed using MATLAB/SIMULINK tool.

Moreover, to overcome the intermittent problem of grid-connected WPP, the authors of [4] suggested the following three approaches. The first is adding a dispatchable power plant such as hydro, thermal diesel power plant, etc. The second approach is integrating WPP with the utility grid system instead of a standalone system. The third one is connecting WPP to an energy storage technology (EST) used as a reserve of energy during peak periods or low wind energy production periods. Currently, the third approach (connecting WPP with EST) is the best solution for compensating the intermittency of wind energy resources, since EST has various benefits than other approaches, including balancing demand and supply, controlling system frequency and voltage, increasing the existing system efficiency, smoothing the output power, and reducing greenhouse gases (GHG) emissions [4]. In addition to this, the authors of [14] reviewed ESTs application potentials for mitigating the fluctuation of renewable energy sources in the utility grid integration sector. This work analyzed the overall comparison of EST systems based on their technical, economic, and environmental fulfillment. As a result, the best suitable EST for renewable energy 
sources (like solar and wind) is selected. Furthermore, the techno-economic analysis of ESTs for grid-integration applications is presented in $[15,16]$. The capacity or size of EST is considered based on the nominal capacity of WPP; the size of EST is recommended 3\% up to $5 \%$ of the rating capacity of the output power of WPP [4].

As noted above, although different studies were conducted to evaluate the performance of grid-connected WTGs, there is a dire need for precise modeling and simulation of a network representing WTGs connected with a grid system. In addition to this, most of the literature is focused on a single mode of operation of WTGs to analyze the performances of grid-connected WTGs.

This study, therefore, aims to evaluate the performance of grid-connected WTGs. Our key research question is, therefore, how does a large-scale grid integrated WPP affect the performances of the power system during constant rated wind speed, variable wind speed, and dynamic transient operation conditions? Moreover, the following procedures are followed to evaluate the performances of grid-connected WTGs. First, a network representing SCIG and DFIG wind turbines connected with a grid network is modeled using MATLAB/SIMULINK. Then, the performances of SCIG and DFIG wind turbines are simulated under four different selected scenarios, including constant rated wind speed, variable wind speed, steady-state, and dynamic transient operating conditions. Finally, simulation results are analyzed in terms of grid and WTGs terminal parameter values. Furthermore, the results of this study will facilitate the selection of the most appropriate WTG for grid integration applications. Also, this work provides the performance analysis results of grid-connected SCIG and DFIG wind turbines during steady-state and transient operation conditions using MATLAB/SIMULINK model for researchers, power system operators, and wind turbine manufacturers.

The paper is organized as follows: Section 2 discuss the fundamentals, advantage, disadvantages, types, characteristics, and topologies of WTGs. Section 3 provides a MATLAB/SIMULINK model and simulation technique for grid-connected SCIG and DFIG wind turbines. Then, Section 4 presents the result and discussion. Finally, Section 5 provides the conclusion of the paper.

\section{Components of Grid-Connected Wind Energy Conversion}

There are different wind energy conversion systems (WECS), such as using fixed-speed wind turbines (FSWT) like SCIG or VSWT (including DFIG and PMSG), and stall-regulated or pitch controlled mechanisms are accessible in the market. Therefore, to select the most suitable WECS components, and perform WPP grid integration studies, understanding the fundamentals, advantages, and disadvantages of parts of WECS is crucial. Figure 1 maps out the main components of grid-connected wind energy sources: wind turbine, gearbox, generator, power electronic converters (AC-DC and DC-AC converters), transformer, and grid. The following subsections review the fundamentals, advantages, disadvantages, and topologies for large-scale grid-connected WTGs. Finally, the detailed model and simulation techniques of WTGs are presented in Section 3.

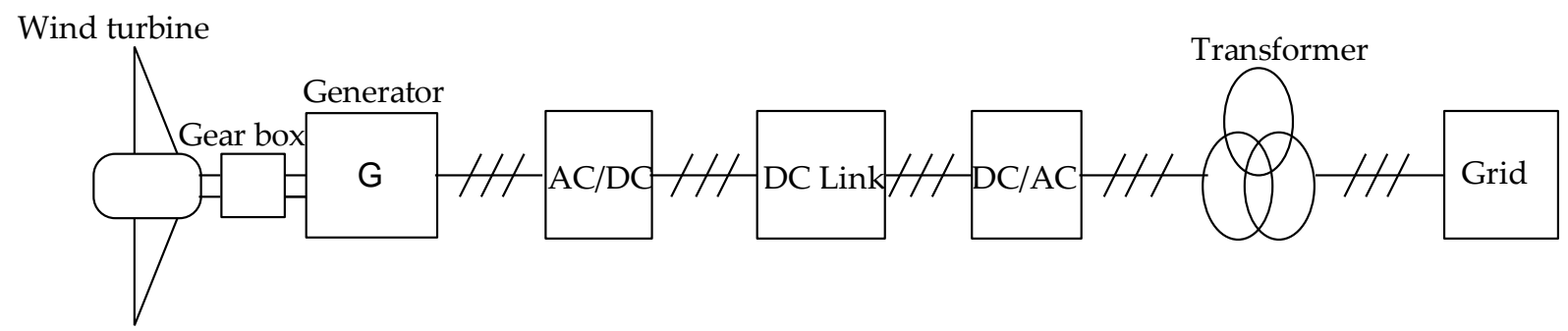

Figure 1. Main components of grid-connected wind energy sources. 


\subsection{Wind Turbine Generators and Topologies}

As shown in Figure 2, three main types of WTGs used for large-scale wind energy production, including SCIG, DFIG, and PMSG, are presented. The following subtopics cover the three types of grid-connected WTGs topologies, advantages, and disadvantages.

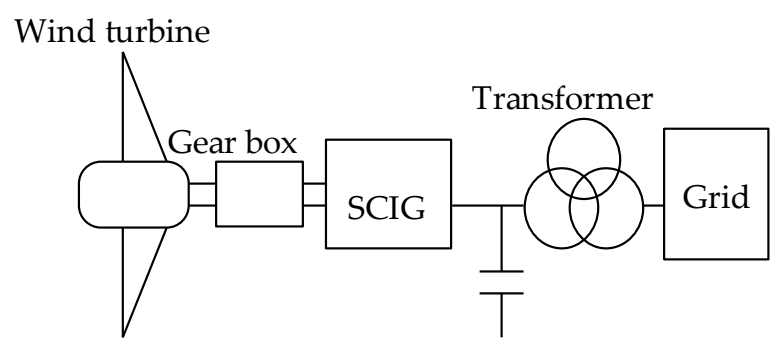

(a) grid-connected SCIG wind turbine

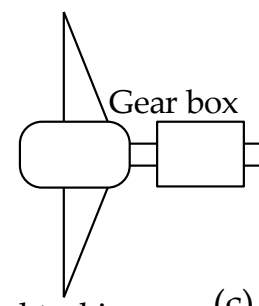

Wind turbine

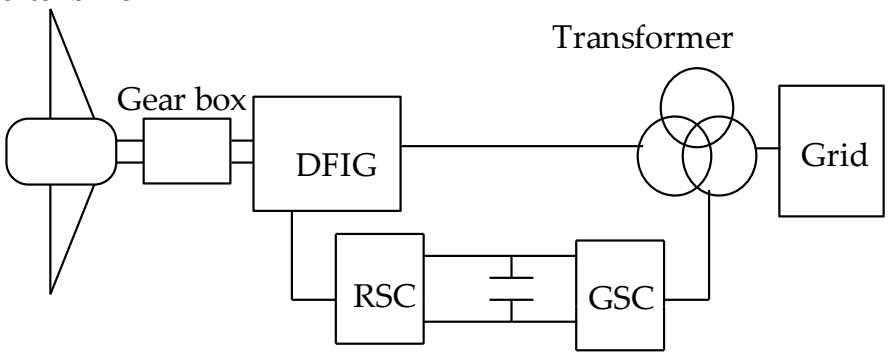

(b) grid-connected DFIG wind turbine

Wind turbine

(c) grid-connected PMSG wind turbine

Figure 2. General topologies for grid-connected three different types of wind turbine generators.

\subsubsection{Squirrel-Cage Induction Generator (SCIG)}

A grid-connected SCIG wind turbine topology is illustrated in Figure 2a. The SCIG wind turbine is connected directly to the grid system. The speed of SCIG is a fixed-speed type, and it used a gearbox to increase the lower rotational speed of WT (45 rpm up to $400 \mathrm{rpm}$ based on the model and the wind velocity) to a high rotational speed of generator (200 rpm up to $800 \mathrm{rpm}$ based on the range of generator rotational speed required [17]. The significant benefits of SCIG are it is robust, reliable, well-proven, and relatively cheap compared to DFIG and PMSG [18,19]. However, SCIG consumes reactive power for its excitation purpose, and it has limited power extracted from wind because the generator is overloaded [20].

\subsubsection{Doubly-Fed Induction Generator (DFIG)}

A grid-connected DFIG wind turbine topology is shown in Figure 2b. Among VSWT types, DFIG uses a gearbox to increase the wind turbine rotational speed. As shown in Figure $2 \mathrm{~b}$, the stator winding of DFIG is directly connected to the grid, and the power electronics converters feeding the rotor winding have a power rating of $\sim 30 \%$ of generator capacity $[17,20]$. A gearbox couples the rotor and generator of DFIG to manage the speed range differences between rotor and generator speed. The rotor winding of DFIG is coupled with a rotor side converter (RSC), and grid side converter (GSC) see Figure $2 b$, whereas the stator winding of DFIG is directly connected to the system grid. Also, a DC-link capacitor is added to decouple the rotor side converter and grid side converter [20]. The main advantages of the DFIG wind turbine are it provides a separate real and reactive power controller, provide a variable-speed operation, is cost-effective compared to PMSG, has a lower converter rating, is lightweight, high efficiency, and the power factor control can be implemented at lower cost and its flexibility [17,21-23]. However, the price of DFIG is higher than SCIG due to the presence of power electronics converters [22]. 


\subsubsection{Permanent Magnet Synchronous Generator (PMSG)}

A grid-connected PMSG wind turbine topology is shown in Figure 2c. Such type of WTG type is a VSWT type, but there is no gearbox coupled with this machine. Because a full-scale power electronics converter is used at both grid and rotor sides, this type of WTG is called direct-drive PMSG. The power electronics converters consist of two IGBTbased converters, including the AC-DC stator side convertor (SSC) and DC-AC grid-side converter (GSC) connected via a DC link. The capacity or rating of power converters is equivalent to the generator output power capacity [20]. As shown in Figure 2c, it is possible to control the turbine speed by applying the controlled type of grid side inverter. However, the main limitations of such configuration are the need for a reactive power compensator and filter for harmonic distortions. The significant benefits of PMSG are it is a self-excited type of generator, it has high starting torque, high power density, smaller in size, direct-driven (no need of gearbox), better reliability, longer life, low rotational inertia, and high efficiency $[17,24,25]$. Compared with DFIG, PMSG has a high performance of grid integration capability. However, PMSG has a higher cost and power loss than others due to the full-scale power converter [11].

\section{System Modeling and Simulation}

A network representing SCIG and DFIG wind turbines with a grid network is modeled and simulated using MATLAB/SIMULINK to study the impacts of integrating wind energy sources with existing grids. There are numerous ways of simulating wind turbine power plants, but the one used for this research is covered in [17,26-29]. The simulation is conducted by considering the same wind speed condition and output power rating for both WTGs. Parameter values of the network and WTGs parameters are mentioned in [29] and reported in Tables 1 and 2. The single line diagram of the WPP integrated into a grid system for the system model is shown in Figure 3. The proposed model of WPP consists of SCIG and DFIG wind turbines. Both the proposed WTGs consist of six units; each unit has an output power rating of $1.5 \mathrm{MW}$. Thus, each WTGs have a total capacity of $9 \mathrm{MW}$ (is obtained from the sum of 6 units of 1.5 MW each).

Furthermore, both SCIG and DFIG wind turbines are connected to a $25 \mathrm{kV}$ distribution system through a $0.575 \mathrm{kV} / 25 \mathrm{kV}$ step-up transformer and exports power to a $120 \mathrm{kV}$ grid through a $25 \mathrm{~km}$ overhead transmission line, $25 \mathrm{kV}$ feeder. A $25 \mathrm{~km}$ long transmission line is applied using the pi-model to consider the power losses between WPP to the grid system. As shown in Figure 3, the grid is a $120 \mathrm{kV}$ system; as a result, the generated power from the wind generator side is stepped up to the grid voltage by using a step-up transform $(25 \mathrm{kV} / 120 \mathrm{kV})$. Furthermore, to protect the grid system from line-to-ground faults, a grounding transformer is connected near to step-up transformer $(25 \mathrm{kV} / 120 \mathrm{kV})$ side. Both WTGs adopt the same network parameters mentioned in Table 1, except a capacitor is connected to the terminal of the SCIG wind turbine to compensate for the reactive power (see Figure 4), and a resistive load is connected to the terminal of the DFIG wind turbine (see Figure 5). Generator and turbine parameter values used for simulation are shown in Table 2. Thus, in this section, the purpose of evaluating the performances of grid-connected wind energy sources is to provide a clear and precise technique of modeling and simulating SCIG and DFIG wind turbines using MATLAB/SIMULINK under the following four operation conditions:

(i) Under constant rated wind speed operation condition: This simulation aims to study the SCIG and DFIG wind 'turbines' power curves at a rated wind speed of $9 \mathrm{~m} / \mathrm{s}$.

(ii) Under variable wind speed operation conditions: This simulation aims to study the impacts of wind speed variations (intermittent problem) of wind energy resources on-grid systems. SCIG and DFIG wind turbine responses were operating under different wind speeds, such as low $(4 \mathrm{~m} / \mathrm{s})$, medium $(8 \mathrm{~m} / \mathrm{s})$, and high $(14 \mathrm{~m} / \mathrm{s})$, are chosen. Furthermore, WTGs parameter responses such as real and reactive power and pitch angle are compared and analyzed. 
(iii) Under steady-state operation condition: This simulation investigates the responses of grid parameters during steady-state(normal) conditions by considering a variable wind speed for both WTGs.

(iv) Under dynamic system transient operation condition: This simulation investigates the response of grid parameters during a fault condition. The dynamic transient state of the system is simulated by applying a three-phase-to-ground fault at the connection bus between B25 and the transmission line. The three-phase-to-ground fault will be cleared after $0.1 \mathrm{~s}$. Variable wind speed is considered for both WTGs.

\section{Wind turbine}

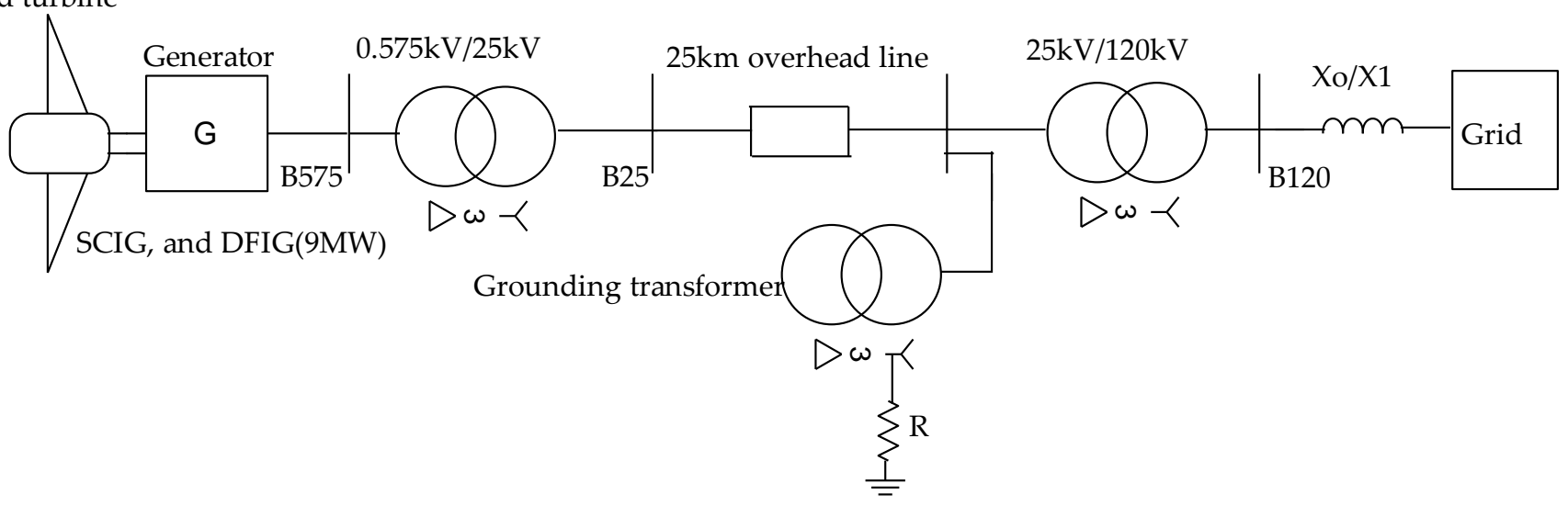

Figure 3. Single line diagram of the wind power plant integrated into a grid system.

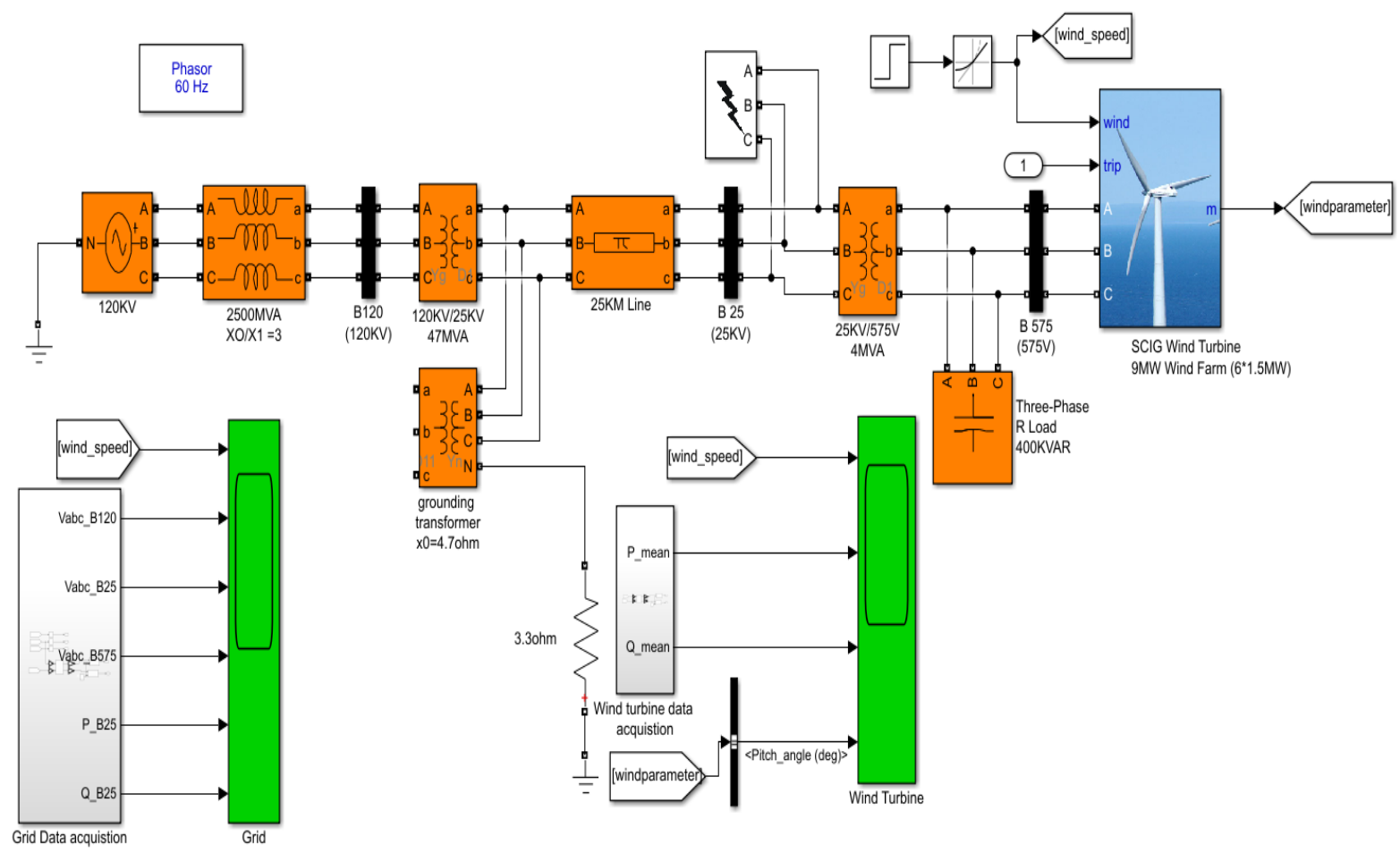

Figure 4. Simulink model of SCIG wind turbine connected to a grid network. 


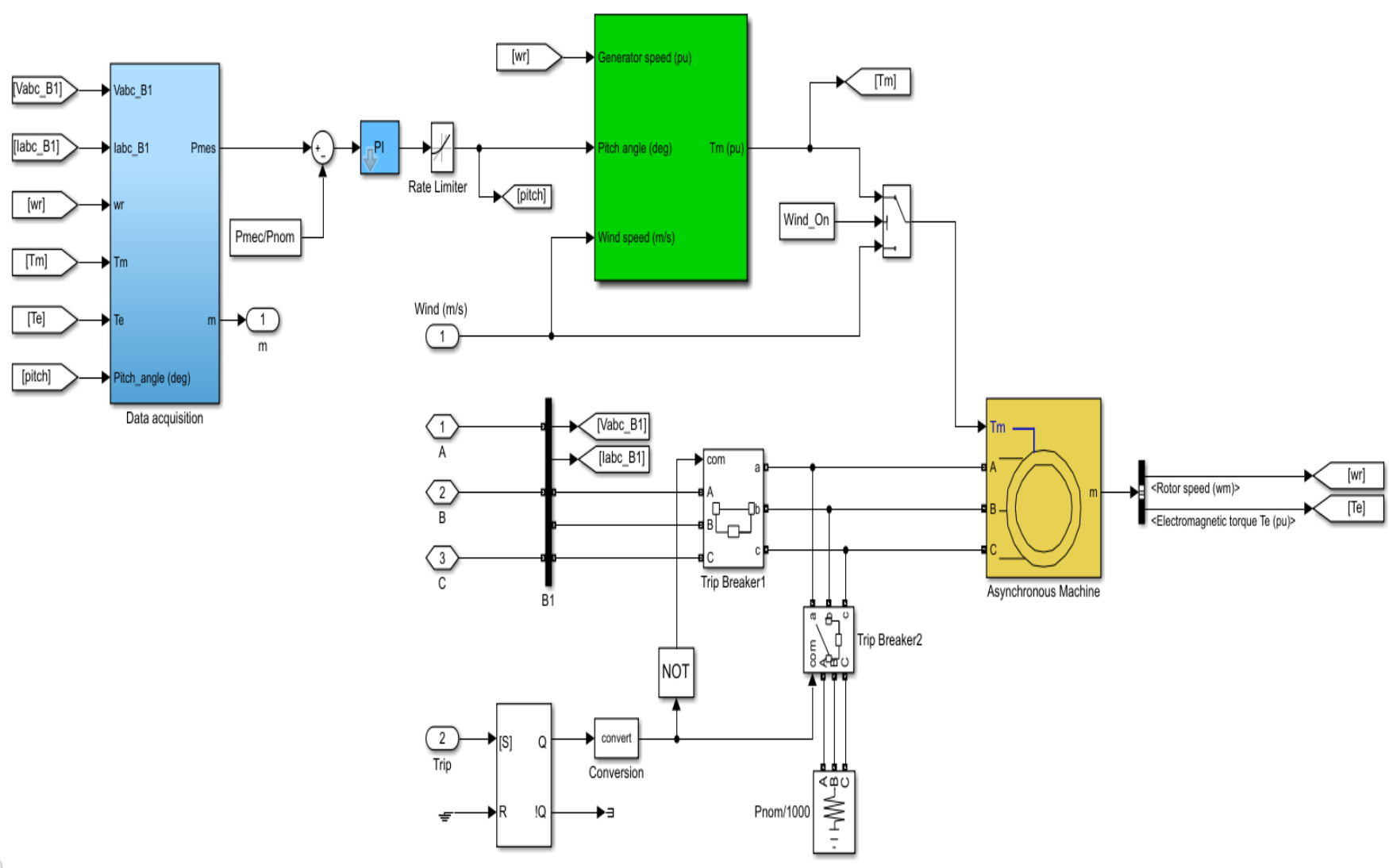

Figure 5. Detail model for SCIG wind turbine and generator under the mask.

Table 1. Network parameter values for simulated SCIG and DFIG.

\begin{tabular}{|c|c|c|c|}
\hline Equipment & Parameter & Value & Unit \\
\hline \multirow{2}{*}{$\begin{array}{l}120 \mathrm{kV} \text { grid } \\
\text { equivalent }\end{array}$} & Nominal voltage & 120 & $\mathrm{kV}$ \\
\hline & Positive sequence phase & 0 & deg \\
\hline \multirow{4}{*}{$\begin{array}{l}\text { Three-phase Mutual } \\
\text { Inductance Z1-Z0 }\end{array}$} & Positive sequence inductance (L1) & 0.015 & $\mathrm{H}$ \\
\hline & Zero-sequence inductance (Lo) & 0.046 & $\mathrm{H}$ \\
\hline & Positive sequence resistances (R1) & 0.576 & $\Omega$ \\
\hline & Zero sequence resistances (Ro) & 1.728 & $\Omega$ \\
\hline \multirow{12}{*}{$\begin{array}{l}\text { Three-phase transformer } \\
\qquad(120 \mathrm{KV} / 25 \mathrm{KV})\end{array}$} & Capacity & 47 & MVA \\
\hline & Winding one connection (ABC terminals) & $\mathrm{Yg}$ & - \\
\hline & Winding two connection $(\mathrm{abc})$ terminals & Delta (D1) & - \\
\hline & Primary voltage & 120 & $\mathrm{kV}$ \\
\hline & Secondary voltage & 25 & $\mathrm{kV}$ \\
\hline & Frequency & 60 & $\mathrm{~Hz}$ \\
\hline & Primary resistance (R1) & 0.002 & pu \\
\hline & Primary inductance (L1) & 0.08 & pu \\
\hline & Secondary resistance (R2) & 0.002 & $\mathrm{pu}$ \\
\hline & Secondary inductance (L2) & 0.08 & $\mathrm{pu}$ \\
\hline & Magnetization resistance (Rm) & 500 & $\Omega$ \\
\hline & Magnetization inductance (Lm) & 500 & $\mathrm{H}$ \\
\hline
\end{tabular}


Table 1. Cont.

\begin{tabular}{|c|c|c|c|}
\hline Equipment & Parameter & Value & Unit \\
\hline \multirow{12}{*}{$\begin{array}{l}\text { Three-phase transformer } \\
(25 \mathrm{KV} / 575 \mathrm{~V})\end{array}$} & Capacity & 4 & MVA \\
\hline & Winding one connection ( $\mathrm{ABC}$ terminals) & $\mathrm{Yg}$ & - \\
\hline & Winding two connection $(\mathrm{abc})$ terminals & D1 & - \\
\hline & Primary voltage & 25 & $\mathrm{kV}$ \\
\hline & Secondary voltage & 575 & $\mathrm{~V}$ \\
\hline & Frequency & 60 & $\mathrm{~Hz}$ \\
\hline & Primary resistance (R1) & 0.0008 & $\mathrm{pu}$ \\
\hline & Primary inductance (L1) & 0.025 & pu \\
\hline & Secondary resistance (R2) & 0.0008 & $\mathrm{pu}$ \\
\hline & Secondary inductance (L2) & 0.025 & pu \\
\hline & Magnetization resistance (Rm) & 500 & $\Omega$ \\
\hline & Magnetization inductance (Lm) & 500 & $\mathrm{H}$ \\
\hline \multirow{9}{*}{ Grounding transformer } & Capacity & 100 & MVA \\
\hline & Primary voltage & 25 & $\mathrm{kV}$ \\
\hline & Secondary voltage & 25 & $\mathrm{kV}$ \\
\hline & Primary resistance (R1) & 0.02506 & $\mathrm{pu}$ \\
\hline & Primary inductance (L1) & 0.752 & $\mathrm{pu}$ \\
\hline & Secondary resistance (R2) & $1 \times 10^{-6}$ & $\mathrm{pu}$ \\
\hline & Secondary inductance (L2) & 0 & $\mathrm{pu}$ \\
\hline & Magnetization resistance (Rm) & 500 & $\Omega$ \\
\hline & Magnetization inductance (Lm) & 500 & $\mathrm{H}$ \\
\hline \multirow{8}{*}{$\begin{array}{l}\text { Feeder (three-phase PI section } \\
\text { line) }\end{array}$} & Positive sequence resistance (R1) & 0.1153 & $\Omega / \mathrm{km}$ \\
\hline & Zero sequence resistance (Ro) & 0.413 & $\Omega / \mathrm{km}$ \\
\hline & Positive sequence inductance (L1) & $1.05 \times 10^{-3}$ & $\Omega / \mathrm{km}$ \\
\hline & Zero sequence inductance (Lo) & $3.32 \times 10^{-3}$ & $\Omega / \mathrm{km}$ \\
\hline & Positive sequence capacitance (C1) & $1.133 \times 10^{-8}$ & $\Omega / \mathrm{km}$ \\
\hline & Zero sequence capacitance (Co) & $5.01 \times 10^{-9}$ & $\Omega / \mathrm{km}$ \\
\hline & length & 25 & $\mathrm{~km}$ \\
\hline & The frequency used for RLC & 60 & $\mathrm{~Hz}$ \\
\hline \multirow{3}{*}{$\begin{array}{l}\text { Capacitor bank (three-phase } \\
\text { series RLC load) for SCIG }\end{array}$} & Nominal voltage (Vn) & 575 & $\mathrm{~V}$ \\
\hline & Capacitive reactive power (Qc) & 400 & KVAR \\
\hline & Nominal frequency & 60 & $\mathrm{~Hz}$ \\
\hline \multirow{3}{*}{$\begin{array}{l}\text { Resistor load (three-phase } \\
\text { series RLC load) for DFIG }\end{array}$} & Nominal voltage (Vn) & 575 & $\mathrm{~V}$ \\
\hline & Nominal frequency & 60 & $\mathrm{~Hz}$ \\
\hline & Active power $\mathrm{P}(\mathrm{W})$ & $5 \times 10^{5}$ & W \\
\hline \multirow{2}{*}{ Bus 575} & Nominal voltage used for pu & 575 & $\mathrm{~V}$ \\
\hline & Base power ( 3 phase) & 10 & MVA \\
\hline \multirow{2}{*}{ Bus B25 } & Nominal voltage used for $\mathrm{pu}$ & 25 & KV \\
\hline & Base power (3 phase) & 10 & MVA \\
\hline \multirow{2}{*}{ Bus B120 } & Nominal voltage used for $\mathrm{pu}$ & 120 & KV \\
\hline & Base power (3 phase) & 10 & MVA \\
\hline
\end{tabular}


Table 2. Generator, turbine, converters, and controller parameter values for simulated SCIG and DFIG.

\begin{tabular}{|c|c|c|c|}
\hline Parameters & SCIG & DFIG & Unit \\
\hline \multicolumn{4}{|c|}{ Generator data } \\
\hline Capacity & 10 & 10 & MVA \\
\hline Nominal voltage (L-L) & $575 \mathrm{Vrms}$ & 575 Vrms & $\mathrm{V}$ \\
\hline Frequency & 60 & 60 & $\mathrm{~Hz}$ \\
\hline Stator resistance (Rs) & 0.004843 & 0.00706 & pu \\
\hline Stator inductance (Lls) & 0.1248 & 0.171 & $\mathrm{pu}$ \\
\hline Rotor Resistance $\left(\mathrm{Rr}^{\prime}\right)$ & 0.004377 & 0.005 & $\mathrm{pu}$ \\
\hline Rotor inductance ( $\left.\mathrm{Llr}^{\prime}\right)$ & 0.1791 & 0.156 & pu \\
\hline Magnetizing inductance (Lm) & 6.77 & 2.90 & $\mathrm{pu}$ \\
\hline Generator inertia constant $(\mathrm{H})$ & 5.04 & 5.04 & s \\
\hline Pole pairs & 3 & 3 & $\mathrm{p}$ \\
\hline Friction factor & 0.01 & 0.01 & $\mathrm{pu}$ \\
\hline \multicolumn{4}{|c|}{ Turbine data } \\
\hline Nominal wind turbine mechanical output power & 9 & 9 & MW \\
\hline Base wind speed & 9 & 9 & $\mathrm{~m} / \mathrm{s}$ \\
\hline Maximum power at base wind speed & 1 & 0.73 & $\mathrm{pu}$ \\
\hline Base rotational speed & 1 & - & $\mathrm{pu}$ \\
\hline Pitch angle controller gain $(\mathrm{kp})$ & 5 & 500 & - \\
\hline Pitch angle controller gain $(\mathrm{ki})$ & 25 & - & - \\
\hline Maximum pitch angle (deg) & 45 & 45 & Degree \\
\hline The maximum rate of change of pitch angle & 2 & 2 & $\mathrm{Deg} / \mathrm{s}$ \\
\hline \multicolumn{4}{|c|}{ Converters data } \\
\hline Converter maximum power & - & 0.5 & $\mathrm{pu}$ \\
\hline Grid-side coupling inductor (L) & - & 0.15 & $\mathrm{pu}$ \\
\hline Grid-side coupling resistor (R) & - & 0.0015 & $\mathrm{pu}$ \\
\hline Nominal DC bus voltage & - & 1200 & $\mathrm{~V}$ \\
\hline DC bus capacitor & - & 0.06 & $\mathrm{~F}$ \\
\hline \multicolumn{4}{|c|}{ Controller data } \\
\hline mode & - & Voltage regulation & - \\
\hline Grid-side converter generated reactive current reference (Iq_ref) & - & 0 & $\mathrm{pu}$ \\
\hline Grid voltage regulator gain $(\mathrm{kp})$ & - & 1.25 & - \\
\hline Grid voltage regulator gain $(\mathrm{ki})$ & - & 300 & - \\
\hline Droop Xs & - & 0.02 & $\mathrm{pu}$ \\
\hline Power regulator gain $(\mathrm{kp})$ & - & 1 & - \\
\hline Power regulator gain $(\mathrm{ki})$ & - & 100 & - \\
\hline Rotor-side converter current regulator gain $(\mathrm{kp})$ & - & 0.3 & - \\
\hline Rotor-side converter current regulator gain $(\mathrm{ki})$ & - & 8 & \\
\hline The maximum rate of change of reference grid voltage & - & 100 & $\mathrm{pu} / \mathrm{s}$ \\
\hline The maximum rate of change of converter reference currents & - & 200 & $\mathrm{pu} / \mathrm{s}$ \\
\hline
\end{tabular}


The following subsections cover the detailed model and simulation techniques of grid-connected SCIG and DFIG wind turbines using MATLAB/SIMULINK.

\subsection{Modeling and Simulation of SCIG}

Figure 4 shows the SCIG wind turbine connected to a grid network. A 9 MW gridconnected SCIG wind turbine is modeled and simulated using MATLAB/SIMULINK. A three-phase voltage source is implemented as an ideal grid for a wind turbine. The stator winding of the SCIG wind turbine is directly connected to a $60 \mathrm{~Hz}, 120 \mathrm{kV}$ grid network. At the same time, a variable-pitch wind turbine drives the rotor. As shown in Figure 4, the reactive power absorbed by the SCIG wind turbine is partially compensated by a capacitor bank connected with the wind turbine at the low voltage bus side (B575). The detailed model for the wind turbine and generator (the inner loop for SCIG) is shown in Figure 5.

\subsection{Modeling and Simulation of DFIG}

Figure 6 illustrates the DFIG wind turbine connected to a grid network. A 9 MW grid-connected DFIG wind turbine is modeled and simulated using MATLAB/SIMULINK. The stator winding of DFIG is directly integrated into $120 \mathrm{kV}, 60 \mathrm{~Hz}$ grid system. In contrast, the rotor is connected to the power grid via back-to-back voltage source converters $(\mathrm{AC}-\mathrm{DC}-\mathrm{AC})$ for the active power $(\mathrm{P})$ and reactive power $(\mathrm{Q})$ levels, control purposes.

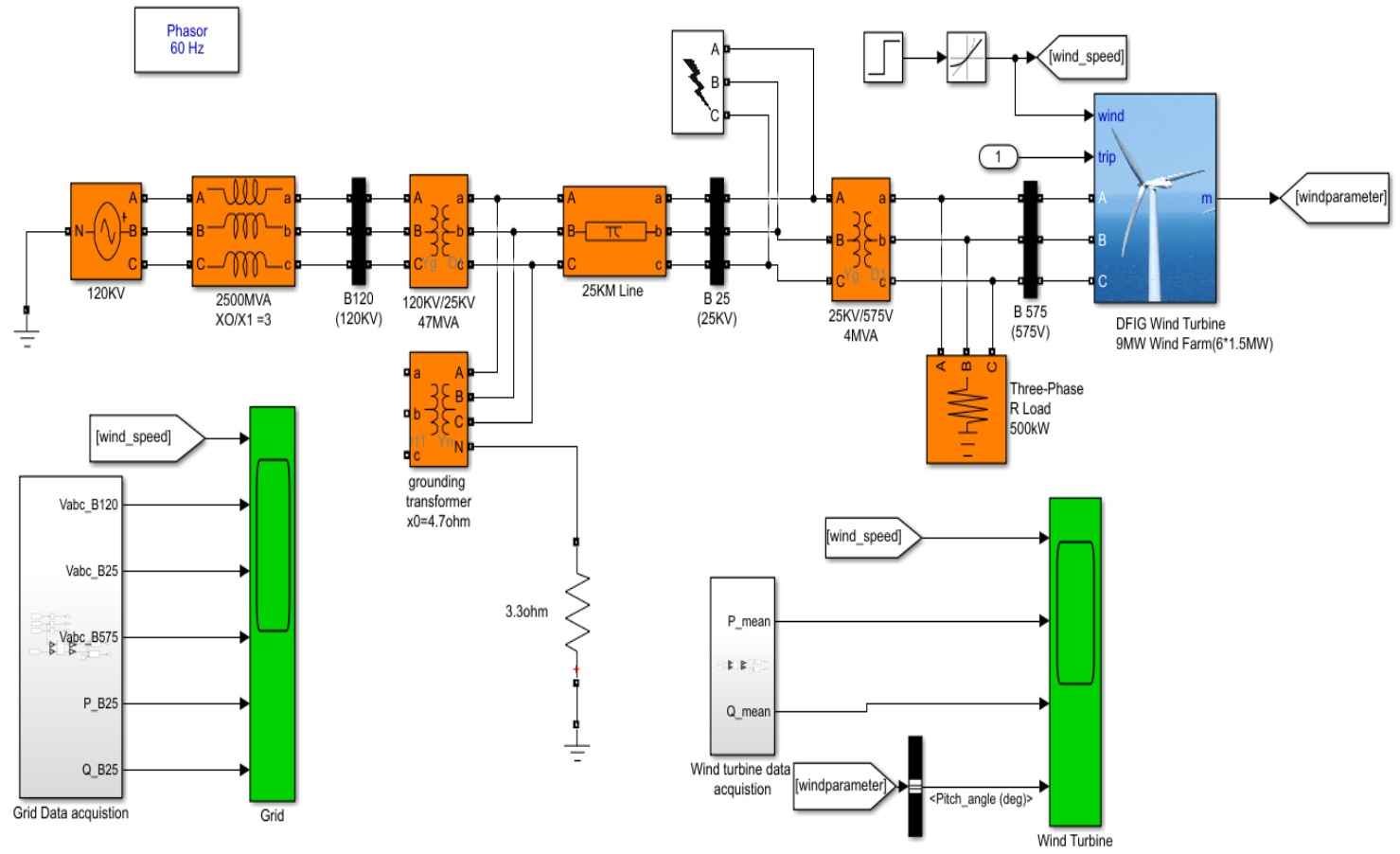

Figure 6. Simulink model of DFIG wind turbine connected to a grid network.

The detailed model of the DFIG wind turbine under the mask is shown in Figure 7a,b. As shown in Figure 7a, the inner loop of the DFIG wind turbine consists of the generatorconvertor subsystem. Moreover, as shown in Figure 7b, the generator-convertor 'subsystem's inner loop consists of a detailed model for a converter and control subsystem. 

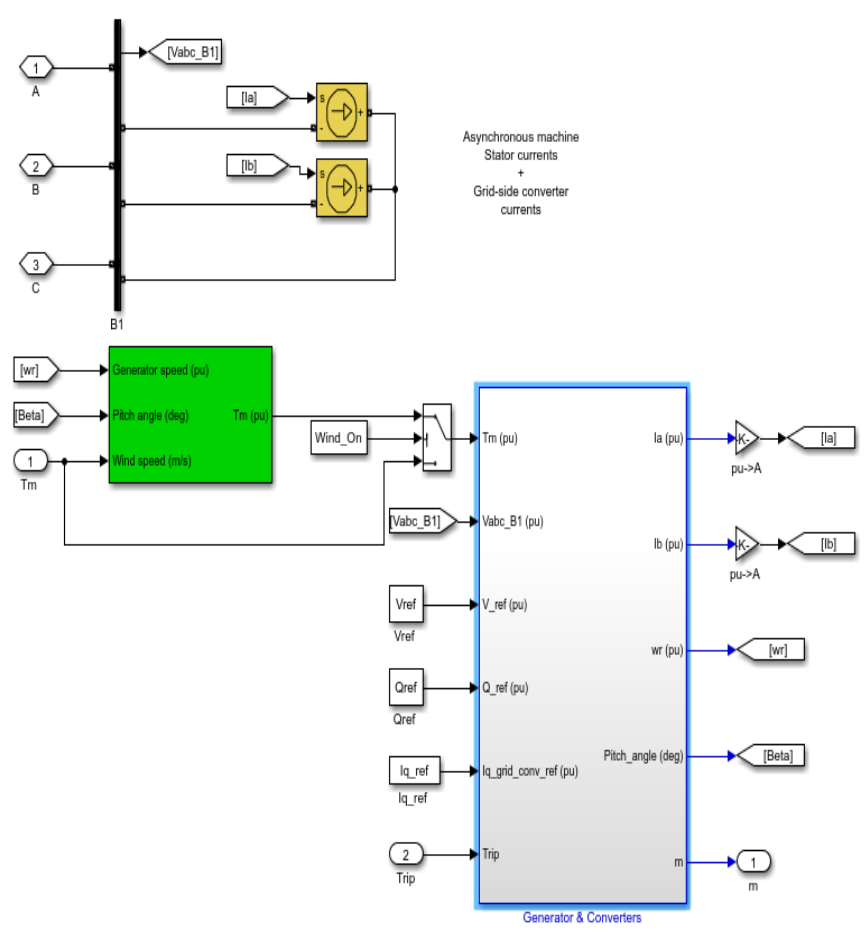

(1)

(a)

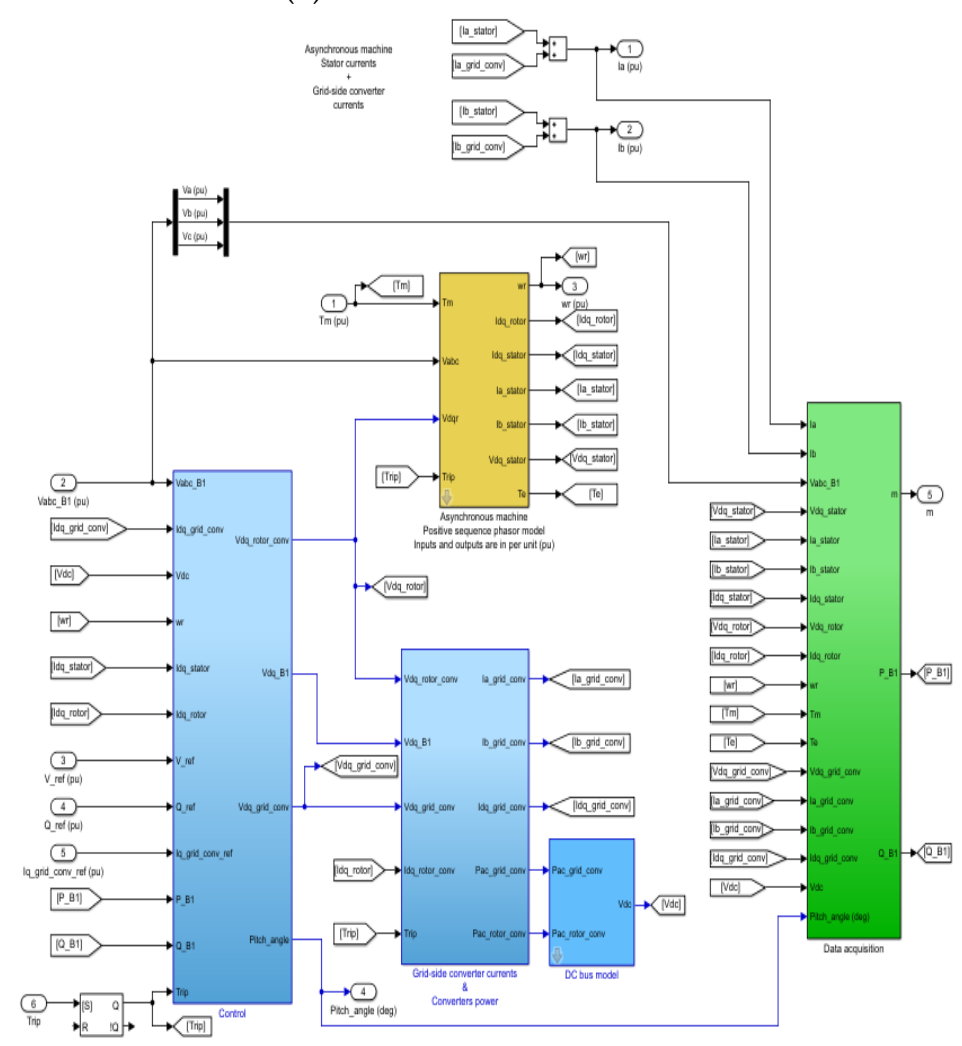

(b)

Figure 7. Detail model for DFIG generator, wind turbine, and converter under the mask. (a) DFIG generator and converter subsystem under the mask. (b) The inner loop for the generator and converters subsystem. 


\section{Simulation Results and Discussion}

The simulation results in this section illustrate the four operational conditions (scenarios) selected and mentioned in Section 3. For all specified operating conditions of WTGs, the results of SCIG and DFIG wind turbines are compared and analyzed in terms of positive sequence voltages (at B575, B25, and B120), active, and reactive power at grid terminals. And active power, reactive power, and pitch angle at WTGs terminals. The whole simulation lasts for $25 \mathrm{~s}$, and for dynamic transient simulation, the fault clearing time is considered $0.1 \mathrm{~s}$.

\subsection{SCIG and DFIG Wind Turbines Power Curves}

The SCIG and DFIG wind 'turbines' power curves showing the variation of turbine output power with speed are illustrated in Figures 8 and 9, respectively. Constant rated wind speed $(9 \mathrm{~m} / \mathrm{s})$ is considered for both WTGs. The generated output power of the SCIG and DFIG wind turbines depends on the wind speed, generator speed, and pitch angle. As shown in Figures 8 and 9, turbine mechanical power is shown as a function of turbine speed to wind speed ranged between $4 \mathrm{~m} / \mathrm{s}$ to $10 \mathrm{~m} / \mathrm{s}$ for SCIG, and $4 \mathrm{~m} / \mathrm{s}$ to $12 \mathrm{~m} / \mathrm{s}$ for DFIG wind turbine, respectively. As illustrated in Figure 8, for SCIG, the maximum turbine output power $(1 \mathrm{pu})$ can be captured at a pitch angle of zero degrees and a rated wind speed of $9 \mathrm{~m} / \mathrm{s}$. Thus, a minimal change in the pitch angle can lead to a massive difference in the output power. In [27], the SCIG wind turbine power curve has been simulated, but the simulation result is not clearly explained and compared with other types of WTGs like DFIG and PMSG.

Similarly, as illustrated in Figure 9, for the DFIG wind turbine, output power at point $\mathrm{C}$ is $0.73 \mathrm{pu}$; at zero pitch angle and rated wind speed of $9 \mathrm{~m} / \mathrm{s}$. Moreover, as shown in Figure 9, both WTGs operate under three operating regions. The first operating region is cut-in speed (point A-B) at a wind speed of $4 \mathrm{~m} / \mathrm{s}$. As the wind speed increases at this operating region, the turbine starts rotating and generating electric power. The second operating region is rated wind speed (point B-C). At this region, as the wind speeds increase above the cut-in speed, the generated electrical output power rises until it reaches a limit. In this case, the wind speed limit for DFIG and SCIG is $9 \mathrm{~m} / \mathrm{s}$. Finally, the third operating region is cut-out speed (C-D). When the wind speed exceeds the rated speed at this active region, the WTGs shut down (stop generating energy) to prevent damage. The controlling system is done by adjusting the blade angle (pitch control mechanism) to keep the power constant.

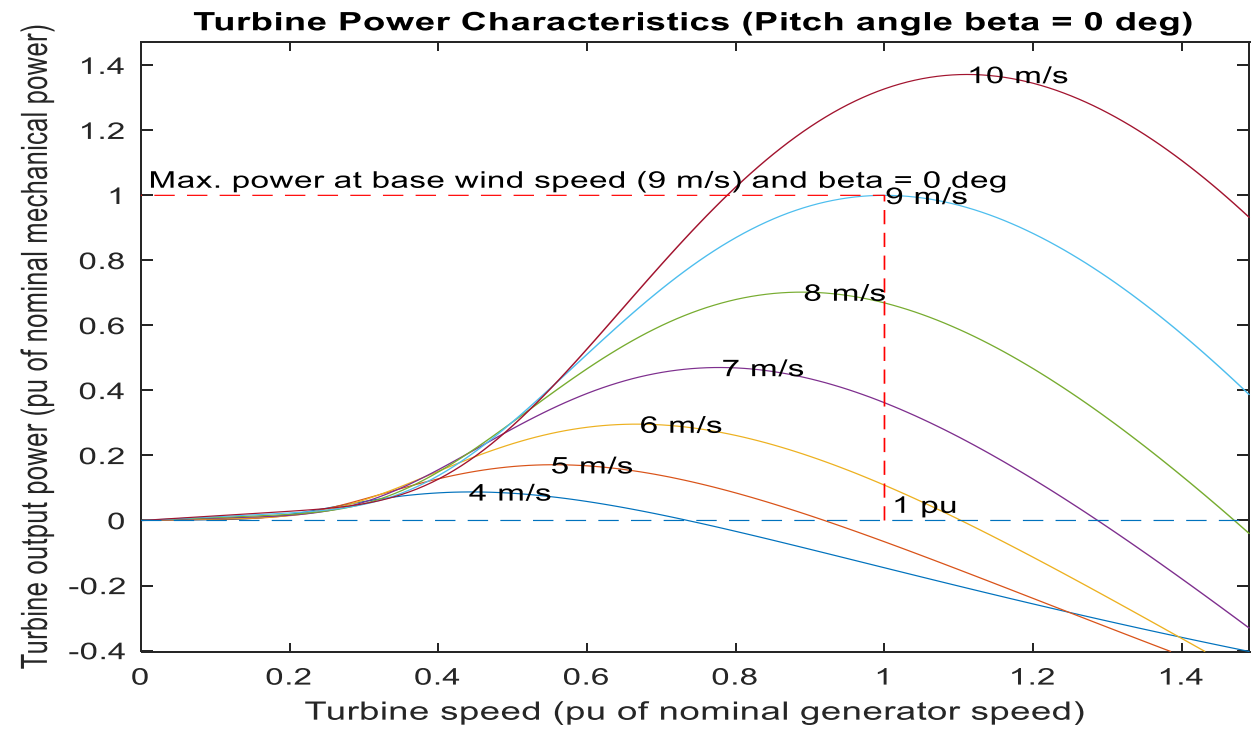

Figure 8. SCIG wind turbine power curve. 


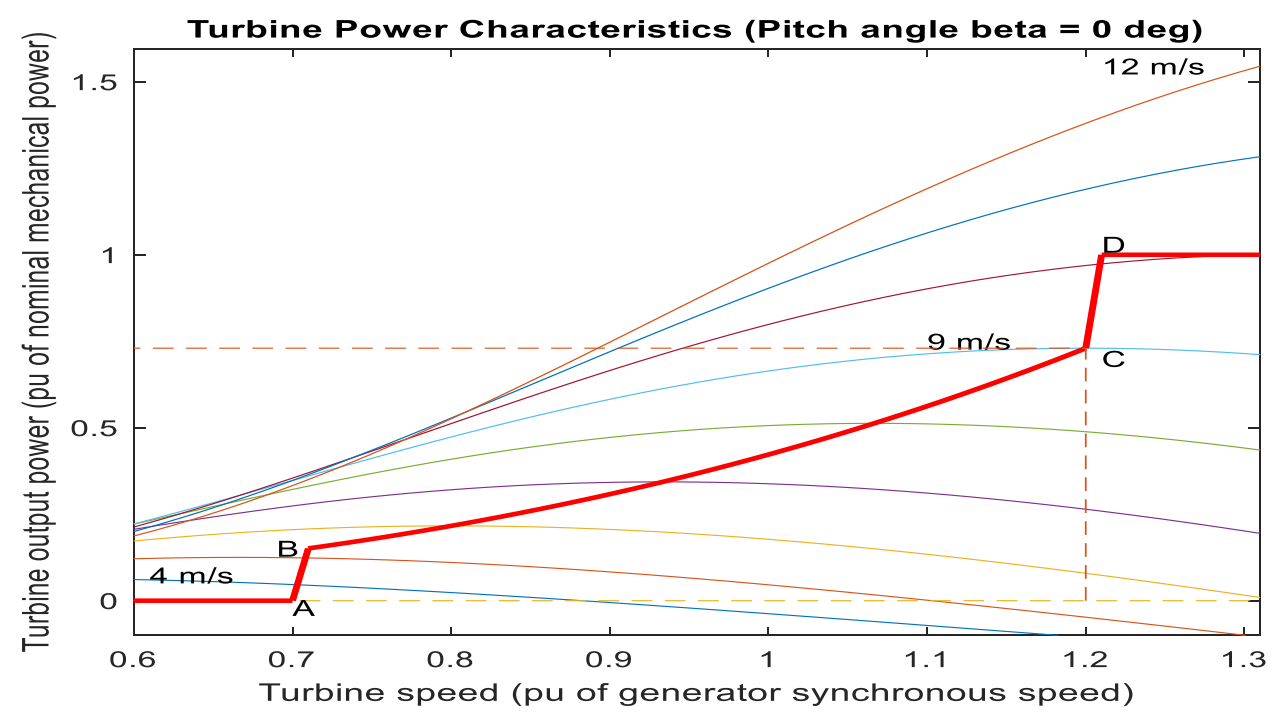

Figure 9. DFIG wind turbine power curve.

\subsection{Impacts of Variable Wind Speed on the Output Power of SCIG and DFIG Wind Turbines}

A MATLAB/SIMULINK model and simulation are performed by considering the wind turbines operated under variable wind speeds. This simulation is conducted to evaluate the impact of variable wind speed (intermittent problem of wind energy sources) integrated into the grid system. A similar simulation has been conducted in [28]. In this study, different WTGs were compared in a single parameter (active power) values only.

The variable wind speed pattern for the whole simulation is considered based on the following wind speed sequences. The wind speed is constant $(4 \mathrm{~m} / \mathrm{s})$ from $t=0 \mathrm{~s}$ to $\mathrm{t}=2 \mathrm{~s}$, it increases from $4 \mathrm{~m} / \mathrm{s}$ to $14 \mathrm{~m} / \mathrm{s}$ from $\mathrm{t}=2 \mathrm{~s}$ to $\mathrm{t}=12 \mathrm{~s}$ with $2 \mathrm{~s}$ time steps. Then wind speed is remained constant $(14 \mathrm{~m} / \mathrm{s})$ from $t=12 \mathrm{~s}$ to $t=25 \mathrm{~s}$. The rated wind speed $(9 \mathrm{~m} / \mathrm{s})$ for both WTGs is considered. The MATLAB simulation output results for variable wind speed with corresponding wind turbine parameters such as real and reactive power and pitch angle for both SCIG and DFIG wind turbines are shown in Figures 10 and 11, respectively. As shown in Figure 10, maximum output power for SCIG wind turbine is generated at a rated wind speed of $9 \mathrm{~m} / \mathrm{s}$ and a pitch angle of zero degrees. At rated wind speed $(9 \mathrm{~m} / \mathrm{s})$, the generated active power is $9 \mathrm{MW}$. However, when the output power of the SCIG wind turbine is increased above its maximum value at wind speed beyond the rated wind speed (at $t=7 \mathrm{~s}$ ), the pitch angle of the turbine starts controlling the wind turbine to limit the generator output power (see Figure 10). Besides, as shown in Figures 10 and 11, the generated output power of SCIG and DFIG wind turbines is directly proportional to the wind speed. For instance, as shown in Figure 10, the generated active power is zero at a wind speed of $4 \mathrm{~m} / \mathrm{s}$ and $14 \mathrm{~m} / \mathrm{s}$, respectively; the SCIG wind turbine operates at a cut-in speed of $4 \mathrm{~m} / \mathrm{s}$ cut-out speed at $14 \mathrm{~m} / \mathrm{s}$, respectively. However, the SCIG wind turbine starts generating output power at wind speed greater than the cut-in speed $(4 \mathrm{~m} / \mathrm{s})$, and the output power is increased until it reaches the rated wind speed $(9 \mathrm{~m} / \mathrm{s})$ at $\mathrm{t}=7 \mathrm{~s}$.

Moreover, as illustrated in Figure 11, the reactive power produced by the DFIG wind turbine is almost zero; this indicates that the DFIG wind turbine operates at a unity power factor. Also, compared to SCIG, the DFIG wind turbine allows generating maximum energy for low wind speeds by optimizing the turbine speed. For instance, the DFIG wind turbine starts generating output power at a wind speed of $4 \mathrm{~m} / \mathrm{s}$. At a wind speed of $4 \mathrm{~m} / \mathrm{s}$, the generated active power is $2 \mathrm{MW}$. Whereas, at a wind speed of $4 \mathrm{~m} / \mathrm{s} \mathrm{SCIG}$ wind turbine generate almost zero output active power. 

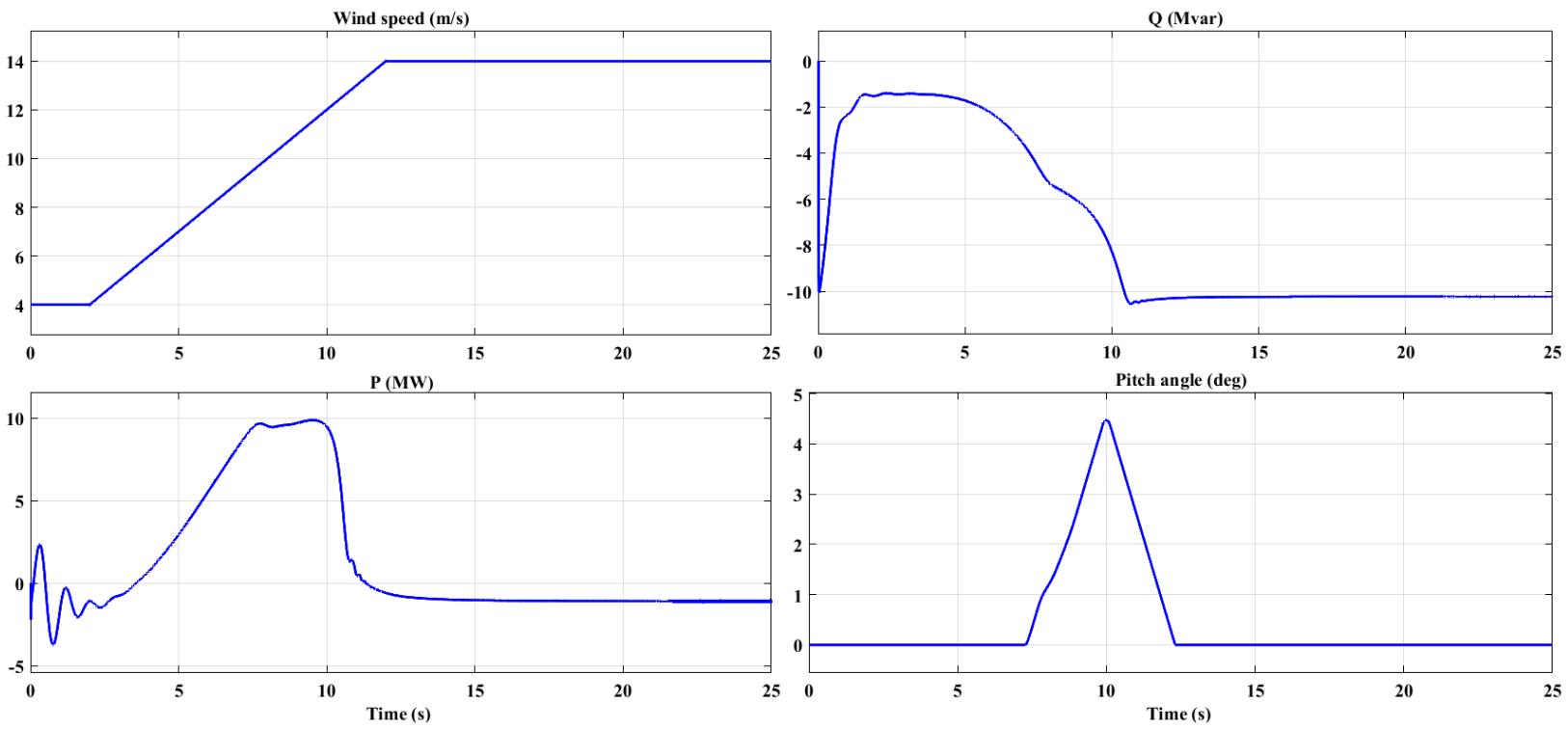

Figure 10. SCIG Wind turbine response at variable wind speeds.
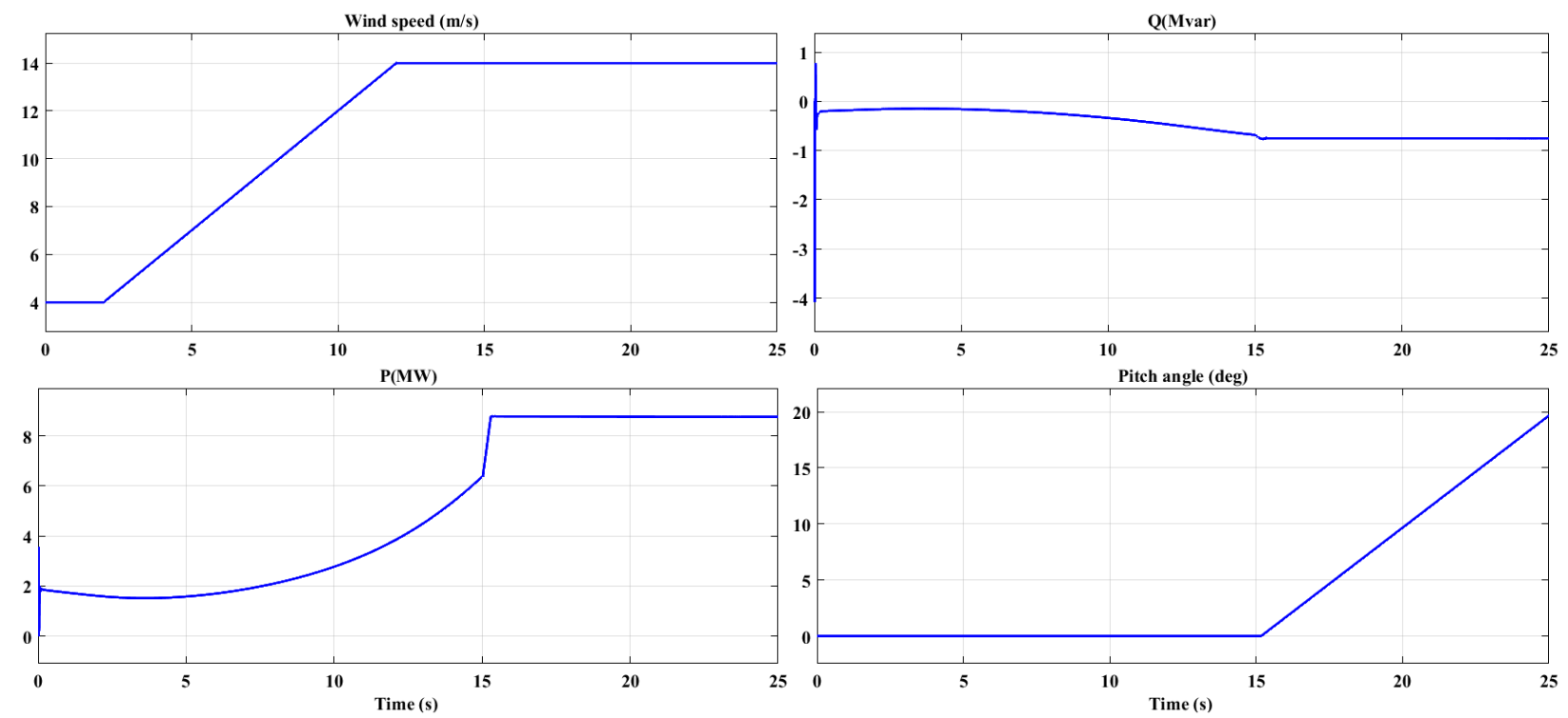

Figure 11. DFIG Wind turbine response at variable wind speeds.

\subsection{Responses of the Grid during Steady-State Operation Condition}

A MATLAB/SIMULINK is performed by considering a variable wind speed to investigate the responses of grid parameters during steady-state(normal) operation conditions. The MATLAB simulation output results with corresponding grid parameters such as active and reactive power and positive sequence voltages at B575, B25, and B120 for both WTGs are shown in Figures 12 and 13, respectively. In [26], the MATLAB/SIMULIK simulation for SCIG operating under normal conditions have been conducted; but the simulation result is not compared with other WTGs.

As shown in Figure 12, the positive sequence voltages of B575, B25, and B120 at normal conditions are simulated. As a result, the voltage magnitude of bus B575 and B25 has decreased from $1 \mathrm{pu}$ to $0.6 \mathrm{pu}$, respectively. Similarly, the voltage magnitude of bus B120 decreased from $1 \mathrm{pu}$ to $0.992 \mathrm{pu}$. This result indicates that the grid 'system's voltage magnitude is reduced due to the characteristics of the SCIG wind turbine during variable wind speed conditions. The grid voltage magnitudes are varied accordingly when the wind speed is varied below and above the rated wind speed. Whereas DFIG wind turbine 
grid parameters, including all voltage magnitudes (B575, B25, and B120), are constant $(1 \mathrm{pu})$, this indicates that the output voltage of DFIG is constant during variable wind speed conditions due to its voltage regulation capability (see Figure 13). Moreover, as shown in Figure 12, as the active power of SCIG increases, reactive power also increases. In contrast, the reactive power of the DFIG wind turbine is zero due to DFIG wind turbines, have a separate real and reactive power controller.
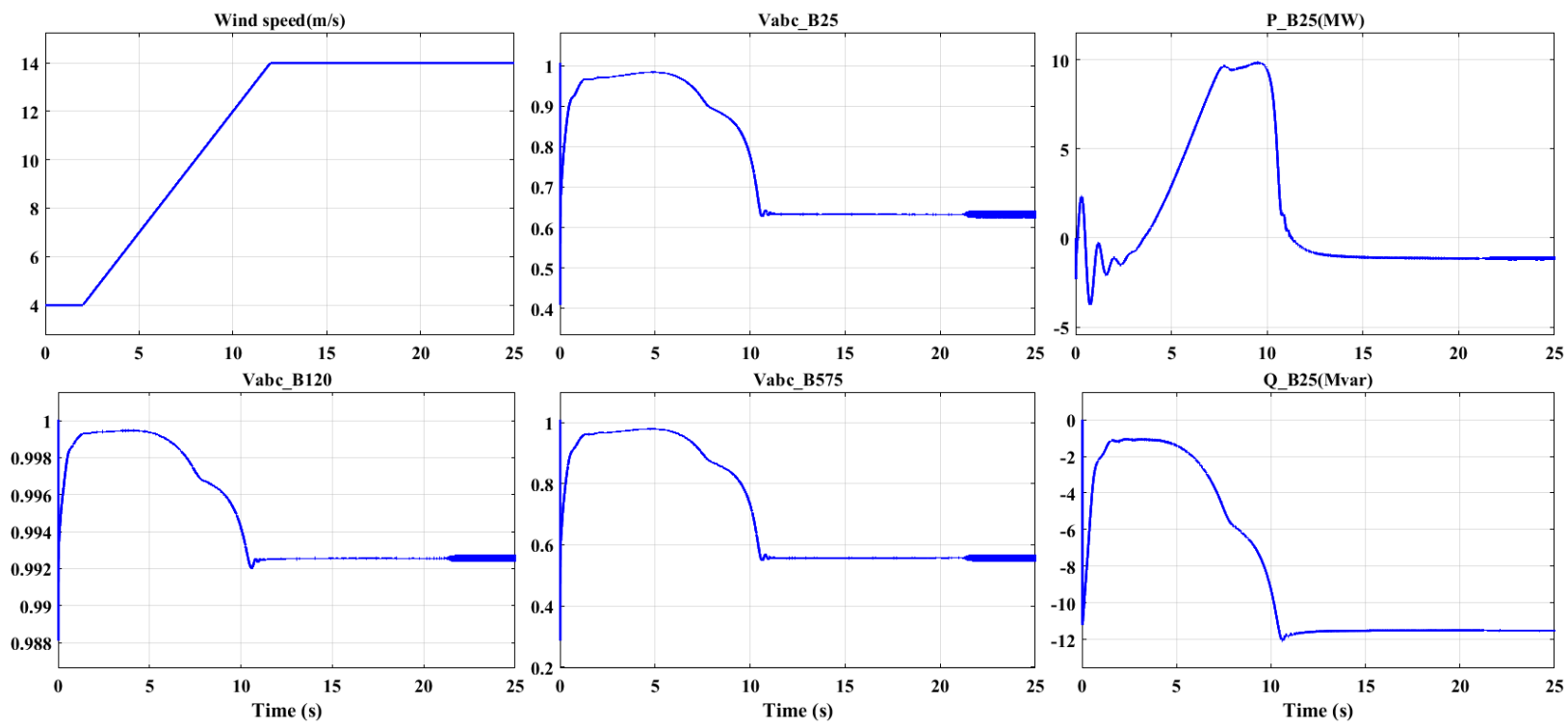

Figure 12. SCIG gird parameters at steady-state operation condition.
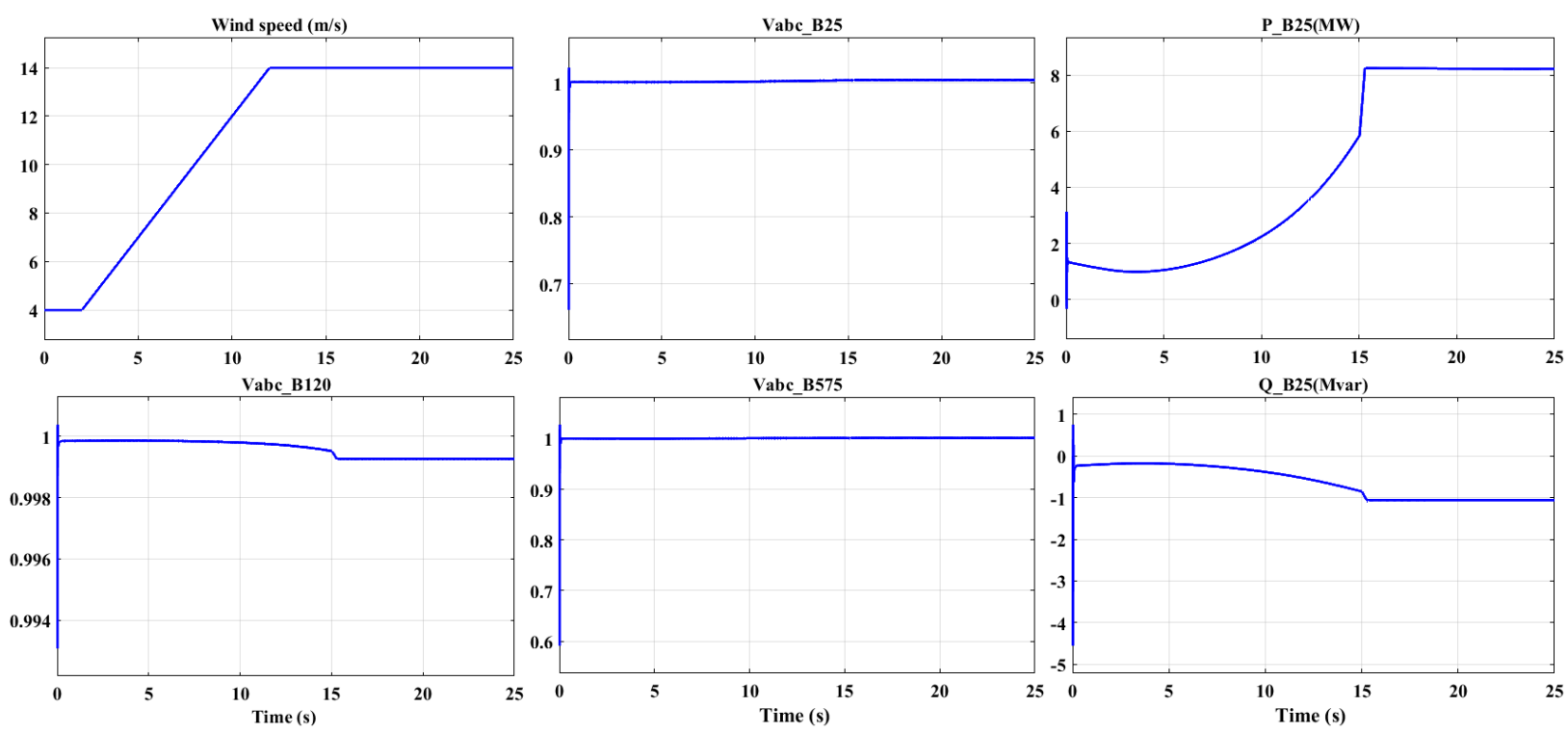

Figure 13. DFIG gird parameters at steady-state operation condition.

\subsection{Responses of the Grid during Transient Operation Condition}

A three-phase short circuit fault on the grid is simulated to study the responses of grid parameters during dynamic system transient (fault) operation conditions. Similarly, in [26], the MATLAB/SIMULIK simulation for SCIG operating under fault conditions has been conducted; but the simulation result is not compared with other WTGs.

The real and reactive power response, positive sequence voltages at B575, B25, and B120 for both WTGs are illustrated in Figures 14 and 15. The simulation is conducted by considering a variable wind speed. For both WTGs, a three-phase short circuit fault is 
applied to the network near bus B25 (see Figures 4 and 6). The fault started at $10 \mathrm{~s}$ and cleared at $10.1 \mathrm{~s}$.

Figures 14 and 15 show that the grid voltage magnitudes have fluctuated when the fault begins and ends. For example, as illustrated in Figure 14, the grid voltage at B120 drops from 0.995 to $0.98 \mathrm{pu}$ at $\mathrm{t}=10 \mathrm{~s}$. Similarly, the voltage magnitudes of bus B25 and B575 decreased from $0.6 \mathrm{pu}$ to $0 \mathrm{pu}$ at $\mathrm{t}=10 \mathrm{~s}$. Besides, as shown in Figure 15, the grid voltage at B120, B25, and B575 are dropped from 1 to $0.98 \mathrm{pu}, 1$ to $0 \mathrm{pu}$, and 1 to $0 \mathrm{pu}$, respectively, at $t=10 \mathrm{~s}$. Thus, the magnitudes of B25 and B575 drop to zero for both SCIG and DFIG during the three-phase fault because the three-phase fault has occurred near bus B575 and B25.

Moreover, the real and reactive output power for both WTGs cases at B25 fluctuated during the three-phase fault. For instance, as shown in Figures 14 and 15, the reactive power consumption for both WTGs increases sharply during the fault and then drops back to steady-state operation conditions. Therefore, according to the simulation result shown in Figures 14 and 15, the power system suffers a fluctuation but finally reaches a steady state after the fault is cleared.
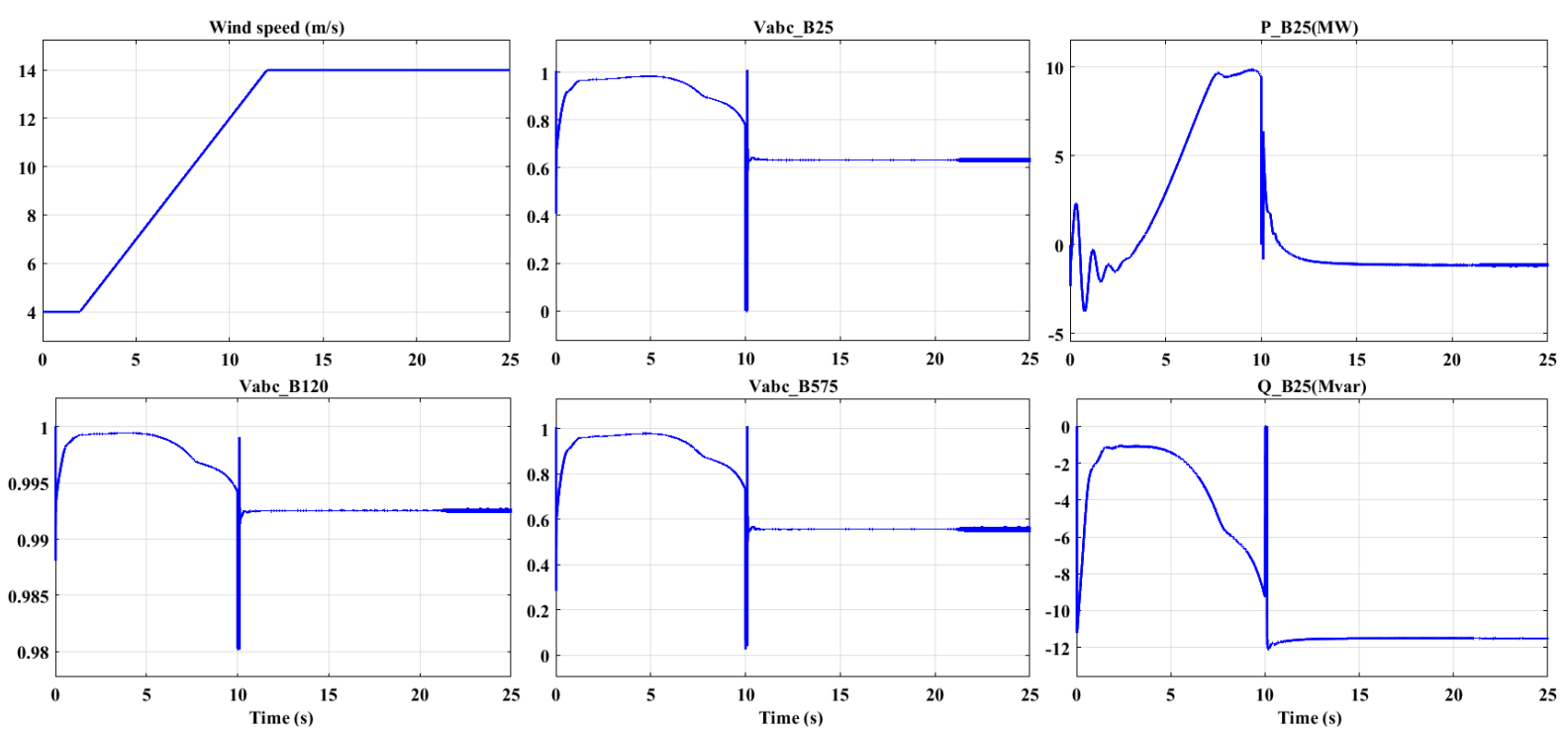

Figure 14. SCIG grid parameters at three phases short circuit fault for $0.1 \mathrm{~s}$.
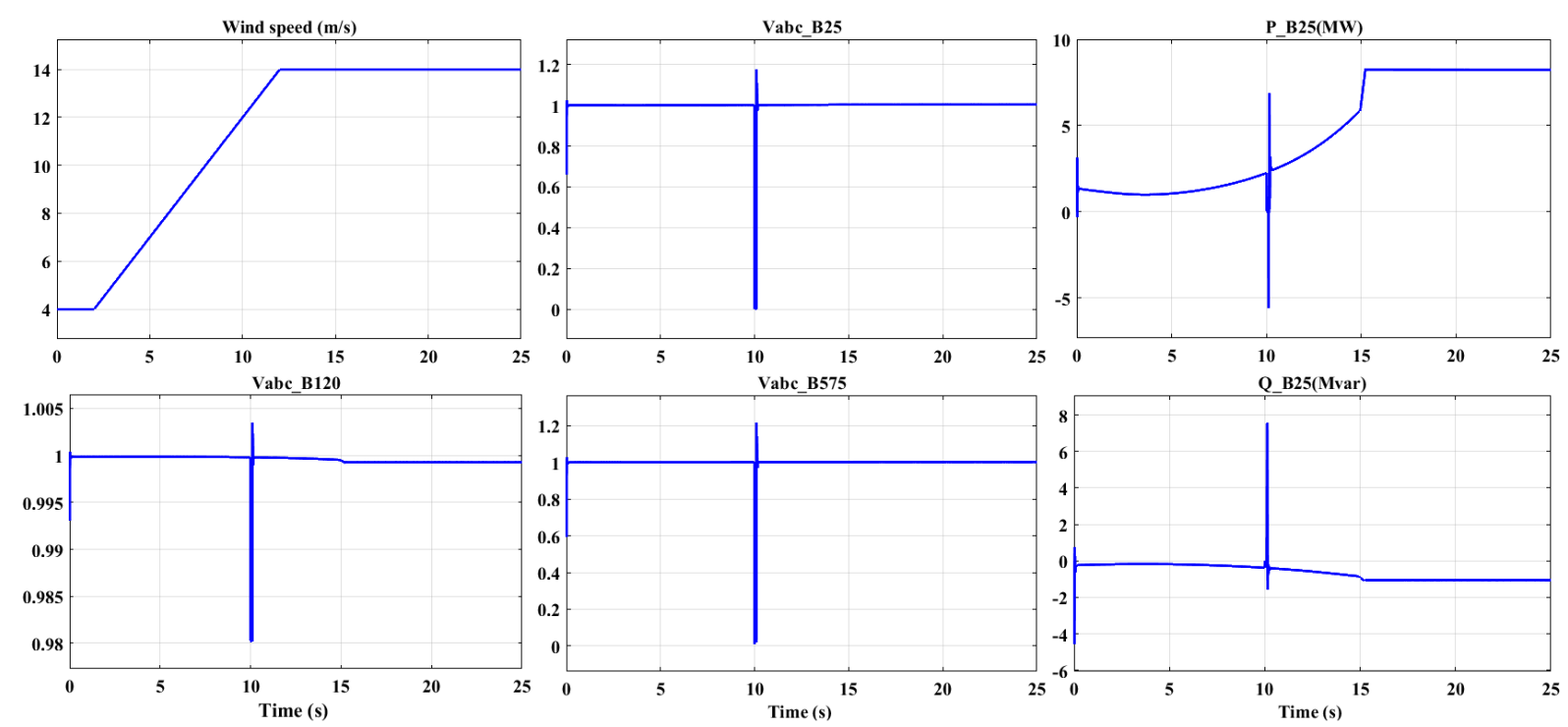

Figure 15. DFIG grid parameters at three-phases short circuit fault for $0.1 \mathrm{~s}$. 


\section{Conclusions}

This paper presented a straightforward performance evaluation technique for gridconnected SCIG and DFIG wind turbine generators. The performances of SCIG and DFIG wind turbines have been simulated and analyzed under four different selected scenarios, including constant rated wind speed, variable wind speed, steady-state operation, and dynamic system transient operating conditions. Thus, evaluating the performances of grid-connected SCIG and DFIG wind turbines clearly, and precisely all selected scenarios are compared and analyzed using MATLAB/SIMULINK models. Based on the evaluation of four scenarios, the study results and conclusion are:

- At constant rated wind speed operation conditions, the generated output power of SCIG and DFIG wind turbines depends on the wind speed, generator speed, and pitch angle. Therefore, a tiny change in the pitch angle can lead to a massive shift in the output power.

- At variable wind speed operation conditions, during the wind speed is varied, the generated-out power of SCIG and DFIG also varied accordingly; this is because the output power of the wind turbines is directly proportional to the wind speed. Therefore, even though the output power of WTGs is directly proportional to the wind speed, compared to SCIG, the DFIG wind turbine can generate maximum output power with a wide range of wind speed.

- At steady-state operation conditions, responses of grid voltage magnitudes of SCIG is decreased from nominal value ( $1 \mathrm{pu}$ ) to a minimum of $0.6 \mathrm{pu}$ due to the characteristics of SCIG wind turbine during variable wind speed condition. In contrast, responses of grid voltage magnitudes of DFIG wind turbine are constant (1 pu) under steady-state operation conditions. In addition, as the SCIG wind turbine's active power increases, reactive power also increases. In comparison, the DFIG wind turbine's reactive power is zero because DFIG has a separate real and reactive power controller.

- At transient operation conditions, grid parameters such as voltage magnitudes at buses and real and reactive output power for SCIG and DFIG wind turbines fluctuated during three-phase fault begins and ends. However, the grid parameters are back to normal condition after the fault is cleared.

Moreover, during variable wind speed operation conditions, the generated output power of the SCIG wind turbine fluctuates at starting time, from $t=0 \mathrm{~s}$ to $\mathrm{t}=2 \mathrm{~s}$; this is because the SCIG wind turbine is directly connected to the grid system without any power converters. Therefore, to overcome such disturbance of grid system during starting time, connecting SCIG wind turbine to the soft starter is recommended. Whereas the generated active power of the DFIG wind turbine is operated smoothly without any disturbance of the grid system, a power converter controls the active and reactive output power of the DFIG wind turbine. Furthermore, connecting renewable energy sources (like solar and wind) with energy storage technologies to the weak utility grid system will also change the result of this study. Therefore, it will be better to evaluate the role of energy storage technologies for grid-connected WTGs.

Author Contributions: H.A.B. modeled the system, analyzing, interpreting the simulation results, and preparing the draft content of the manuscript; M.M. supervised during the study and reviewed and edited the manuscript; T.C., M.B., K.A.F., A.A.K. and J.V.M. reviewed, and edited the manuscript. All authors have read and agreed to the published version of the manuscript.

Funding: This research received no external funding.

Institutional Review Board Statement: Not applicable.

Acknowledgments: Network for Advancement of sustainable Capacity in Education and Research in Ethiopia (NASCERE), Jimma University, Ethiopia, and Vrije Universiteit (VUB), Brussels, Belgium, are acknowledged for providing a joint Ph.D. scholarship to the first author during the study.

Conflicts of Interest: The authors declare no conflict of interest. 


\section{References}

1. Zhang, Y.; Ula, S. Comparison and evaluation of three main types of wind turbines. In Proceedings of the 2008 IEEE/PES Transmission and Distribution Conference and Exposition, Chicago, IL, USA, 21-24 April 2008; pp. 1-6. [CrossRef]

2. International Renewable Energy Agency. Renewable Energy Capacity Highlights. Irena 2020, 1-3. Available online: https: //www.irena.org/publications/2021/March/Renewable-Capacity-Statistics-2021 (accessed on 15 April 2021).

3. Sanchez, A.G.; Molina, M.G.; Rizzato Lede, A.M. Dynamic model of wind energy conversion systems with PMSG-based variable-speed wind turbines for power system studies. Int. J. Hydrogen Energy 2012, 37, 10064-10069. [CrossRef]

4. Ibrahim, H.; Ghandour, M.; Dimitrova, M.; Ilinca, A.; Perron, J. Integration of wind energy into electricity systems: Technical challenges and actual solutions. Energy Procedia 2011, 6, 815-824. [CrossRef]

5. Chowdhury, M.M.; Haque, M.E.; Aktarujjaman, M.; Negnevitsky, M.; Gargoom, A. Grid integration impacts and energy storage systems for wind energy applications-A review. In Proceedings of the 2011 IEEE Power and Energy Society General Meeting, Detroit, MI, USA, 24-28 July 2011; pp. 1-8. [CrossRef]

6. Gupta, A. Integration Challenges of Wind Power on Power System Grid A Review. In Proceedings of the 2018 International Conference on Advanced Computation and Telecommunication (ICACAT), Bhopal, India, 28-29 December 2018; pp. 1-7.

7. Nicolae, I.D.; Nicolae, P.M.; Popa, D.L. Simulation by MATLAB/Simulink of a wind farm power plant. In Proceedings of the 16th International Power Electronics and Motion Control Conference and Exposition, Antalya, Turkey, 21-24 September 2014; pp. 258-263. [CrossRef]

8. Abdel-Khalik, A.S.; Ahmed, K.H. Performance evaluation of grid connected wind energy conversion systems with five-phase modular permanent magnet synchronous generators having different slot and pole number combinations. In Proceedings of the 2011 IEEE International Electric Machines \& Drives Conference (IEMDC), Niagara Falls, ON, Canada, 15-18 May 2011; pp. 1119-1124. [CrossRef]

9. Muljadi, E.; Butterfield, C.P.; Parsons, B.; Ellis, A. Characteristics of variable speed wind turbines under normaland fault conditions. In Proceedings of the 2007 IEEE Power Engineering Society General Meeting, Tampa, FL, USA, $24-28$ June 2007. [CrossRef]

10. Duan, J.; Li, R.; Lin, A. Study of voltage stability in grid-connected large wind farms. In Advanced Materials Research; Trans Tech Publications Ltd.: Bäch, Switzerland, 2012; Volume 433, pp. 1794-1801. [CrossRef]

11. Duong, M.Q.; Le, K.H.; Grimaccia, F.; Leva, S.; Mussetta, M.; Zich, R.E. Comparison of power quality in different grid-integrated wind turbines. In Proceedings of the 2014 16th International Conference on Harmonics and Quality of Power (ICHQP), Bucharest, Romania, 25-28 May 2014; pp. 448-452. [CrossRef]

12. Ye, Y.; Fu, Y.; Wei, S. Simulation for Grid Connected Wind Turbines with Fluctuating. Phys. Procedia 2012, 24, 253-260. [CrossRef]

13. Ahyaten, S.; Bahaoui, J. El Modeling of Wind Turbines Based on DFIG Generator. Proceedings 2020, 63, 16. [CrossRef]

14. Behabtu, H.A.; Messagie, M.; Coosemans, T.; Berecibar, M.; Fante, K.A.; Kebede, A.A.; Van Mierlo, J. A review of energy storage technologies' application potentials in renewable energy sources grid integration. Sustainability 2020, 12, 10511. [CrossRef]

15. Kebede, A.A.; Berecibar, M.; Coosemans, T.; Messagie, M.; Jemal, T.; Behabtu, H.A.; Van Mierlo, J. A techno-economic optimization and performance assessment of a $10 \mathrm{kWP}$ photovoltaic grid-connected system. Sustainability 2020, 12, 7648. [CrossRef]

16. Kebede, A.A.; Coosemans, T.; Messagie, M.; Jemal, T.; Behabtu, H.A.; Van Mierlo, J.; Berecibar, M. Techno-economic analysis of lithium-ion and lead-acid batteries in stationary energy storage application. J. Energy Storage 2021, 40, 102748. [CrossRef]

17. Sumathi, S.; Ashok Kumar, L.; Surekha, P. Solar PV and Wind Energy Conversion Systems; Springer International Publishing: Cham, Switzerland, 2015.

18. Shahni, A.; Qazi, S.H.; Kaloi, G.S.; Ullah, R. Review on Performance Analysis of SCIG and PMSG-Based Wind Energy Conversion System Systems. Int. J. Electron. Commun. Eng. 2019, 6, 1-12. [CrossRef]

19. Saheb-Koussa, D.; Haddadi, M.; Belhamel, M.; Koussa, M.; Noureddine, S. Modeling and simulation of windgenerator with fixed speed wind turbine under matlab-simulink. Energy Procedia 2012, 18, 701-708. [CrossRef]

20. Duong, M.Q.; Grimaccia, F.; Leva, S.; Mussetta, M.; Sava, G.; Costinas, S. Performance analysis of grid-connected wind turbines. UPB Sci. Bull. Ser. C Electr. Eng. Comput. Sci. 2014, 76, 169-180.

21. Abdel-Salam, M.; Ahmed, A.; Mahrous, M. Transient analysis of grid-connected wind-driven PMSG, DFIG and SCIG at fixed and variable speeds. Innov. Syst. Des. 2011, 2, 1-19.

22. Akanto, J.M.; Hazari, M.R.; Mannan, M.A. LVRT and Stability Enhancement of Grid-Tied Wind Farm Using DFIG-Based Wind Turbine. Appl. Syst. Innov. 2021, 4, 33. [CrossRef]

23. Muller, S.; Deicke, M.; De DonckerM, R.W. Doubly Fed Induction Generator System for wind turbines. IEEE 2002, 8, 26-33. [CrossRef]

24. López-Ortiz, E.N.; Campos-Gaona, D.; Moreno-Goytia, E.L. Modelling of a wind turbine with permanent magnet synchronous generator. In Proceedings of the 2012 North American Power Symposium (NAPS), Champaign, IL, USA, 9-11 September 2012. [CrossRef]

25. Baran, J.; Jąderko, A. An MPPT Control of a PMSG-Based WECS with Disturbance Compensation and Wind Speed Estimation. Energies 2020, 13, 6344. [CrossRef]

26. Syahputra, R.; Robandi, I.; Ashari, M. Performance Analysis of Wind Turbine as a Distributed Generation Unit In Distribution System. Int. J. Comput. Sci. Inf. Technol. 2014, 6, 39-56. [CrossRef] 
27. Anish, R.; Kothari, D.P. Modeling and analysis of grid networks with Distributed Resources using MATLAB/SIMULINK. In Proceedings of the PEDES 2012-IEEE International Conference on Power Electronics, Drives and Energy Systems, Bengaluru, India, 16-19 December 2012; pp. 1-6. [CrossRef]

28. Chong, C.H.; Rigit, A.R.H.; Ali, I. Wind turbine modelling and simulation using Matlab/SIMULINK. In Materials Science and Engineering; IOP Conference Series; IOP Publishing: Bristol, UK, 2021; Volume 1101, p. 012034. [CrossRef]

29. Gagnon, R. Wind Farm-DFIG Detailed Model-MATLAB \& Simulink. MathWORKS. 2021. Available online: https://www. mathworks.com/help/physmod/sps/ug/wind-farm-dfig-detailed-model.html;jsessionid=a2a435e13fc5108445d84a28ca36 (accessed on 16 July 2021). 